\title{
BLOGS DE CONTABILIDADE: SOCIALIZAÇÃO DE CONHECIMENTOS
}

\author{
Marcos Laffin \\ marcoslaffin@gmail.com \\ Universidade Federal de Santa Catarina
}

\author{
Talita Clemente Machado Mendes \\ tataaamachado@gmail.com \\ Universidade Federal de Santa Catarina
}

RESUMO: Este texto resulta da pesquisa a respeito do conhecimento contábil e das mídias digitais como formas de interação em comunidades virtuais. A existência de blogs de contabilidade, como mídia digital e instrumento de socialização de conhecimentos, mobilizou a seguinte questão de pesquisa: Quais conteúdos contábeis são socializados nos blogs de contabilidade? O objetivo consistiu em identificar os conteúdos contábeis nos blogs de contabilidade. Para isso, elaborou-se uma pesquisa exploratória e documental, a fim de levantar dados de blogs de contabilidade encontrados na internet no período de 2006 a 2014. Todavia foram analisados apenas aqueles que estavam em atividade no ano de 2014. Inferiuse que eles favorecem uma socialização virtual por meio da pluralidade de temas e conteúdos contábeis divulgados. Além disso, contribuem na formação individual e coletiva, a fim de promover discussões dos temas compartilhados pelos autores, com a intenção de potencializar o desenvolvimento de diferentes conhecimentos na área contábil.

Palavras-chave: Blogs de Contabilidade. Socialização. Interação. Conteúdos.

ABSTRACT: This text results from research on the accounting knowledge and digital media as forms of interaction in virtual communities. The existence of accounting blogs, such as digital media and knowledge socialization tool, mobilized the following research question: What accounting contents are socialized in accounting blogs? The goal was to identify the accounting content in Accounting blogs. For this, we drew up an exploratory and documentary research in order to collect data accounting blogs found on the internet in the 2006-2014 period. However they were analyzed only those who were active in 2014. It is inferred that they favor a virtual socialization through the plurality of themes and accounting contents disclosed. Moreover, contribute to the individual and collective training in order to promote discussions of the themes shared by the authors, with the intention of enhancing the development of different knowledge in accounting.

Keywords: Accounting Blogs. Socialization. Interaction. Contents.

Artigo recebido em: 14/09/2015; Aceito em: 20/10/2015

\section{INTRODUÇÃO}

Comunicação é um processo pelo qual ideias, valores, crenças, práticas, conhecimentos, teorias, sentimentos e outras manifestações da cultura humana são transmitidos e socializados de sujeitos para sujeitos, tornando possível a interação social. Esta transmissão e socialização assumem modos de ações e relações entre integrantes ou grupos de uma sociedade pela qual é possível construir formas de comunicação a fim de dar vida ao conjunto de saberes produzido pelo ser humano (VIGOTSKI, 1998).

Além disso, ela é um dos instrumentos de apropriação dos conhecimentos socialmente produzidos e também sobre as formas de organização social elaborada pela cultura humana. Apesar de, com recorte epistemológico para este estudo, entende-se que comunicação, em 
seus diferentes modos, é a função básica da linguagem e, assim, pode ser compreendida como exercício de diálogo para socializar diferentes saberes. Neste sentido, "a comunicação, expressão da competência mental chamada linguagem, é a capacidade de um ser humano se fazer compreender por outro ser humano e é por meio desse processo de compreensão mútua entre pessoas que os vínculos sociais são criados e a cultura é preservada ou modificada" (VILALBA, 2006, p. 22).

No contexto da comunicação como processo de socialização e desenvolvimento dos sujeitos e das produções humanas, também as formas de comunicação e as linguagens assumem significados diversos e ampliam as formas históricas do seu acontecer. Desse modo, dependendo do contexto, das formas e da interação com o conhecimento, as linguagens podem caracterizar a transmissão ou a produção de novos saberes (WERNECK, 2003).

No âmbito da Contabilidade, inicialmente a forma de transmissão do conhecimento contábil equivalia às formas rudimentares de socialização, contudo foram colaborativas com a divulgação do método das Partidas Dobradas. Este método pode ser considerado um marco histórico para o desenvolvimento do conhecimento contábil, apesar de sua socialização ter sido marcada pela linguagem pragmática da época, e que, segundo relatos, já existia desde 1330. De acordo com Martins (2001, p.112), a divulgação deste método foi divulgada na publicação do "Tractatus de Computis et Scripturis em 1494".

Naquele contexto, eram os livros e outros documentos, geralmente de ordem particular, que registravam o produto do conhecimento. Assim, o saber contábil foi transmitido de geração em geração, constituindo-se num conjunto de práticas de registro e controle do patrimônio. Entretanto, tendo em vista a perspectiva de novos saberes, muitas invenções ocorreram no decorrer da história da civilização humana e conjuntamente nas formas de disseminar o conhecimento (AMORIM, 1999).

$\mathrm{Na}$ atualidade, pelo desenvolvimento das ciências e de novas tecnologias, caracterizase a internet e o uso das plataformas tecnológicas como formas que contribuíram para a democratização da informação e, por conseguinte, na produção de novos conhecimentos e novas formas de interação entre dados, informações e conhecimentos (SCHAFF,1993).

Enquanto os meios de comunicação em massa como: jornais, televisão e até mesmo os rádios transmitiam informações em um único sentido, sujeito - emissor para sujeito - receptor, as mídias sociais trouxeram benefícios como a interatividade, o alcance, a eficácia e uma reconfiguração dos custos, consideravelmente mais baixos se comparados com outras mídias tradicionais (VILABA, 2006).

Atualmente, existem diferentes tipos de mídias sociais (facebook, Orkut, MySpace, Twitter, Blogger, Wordpress, Sónico, Youtube e etc...), com diversas finalidades de públicos, áreas de conhecimento, bem como enfoques, abordagens e metodologias de disseminação. Entre as diversas áreas de conhecimento abordadas por elas, está a Contabilidade. O conhecimento que a Ciência Contábil reúne nos seus mais diferentes temas, os quais são socializados por meio dessas mídias, constitui objeto deste estudo. Todavia, diante das particularidades e contribuições de cada tipo de mídia existente, optou-se em delimitar o estudo aos blogs de Contabilidade (LAFFIN, 2013).

Nos diversos tipos de mídia sociais, o crescente uso dos blogs tem-se destacado como instrumento na socialização de diferentes conteúdos e informações. Logo, identificou-se a temática deste estudo pelo uso desse tipo de mídia como meio de socializar os conhecimentos contábeis por intermédio de diálogos com possíveis interlocutores, estudantes, professores, profissionais e outros interessados nesta forma de comunicação, podendo resultar em novas aprendizagens e no desenvolvimento pessoal e profissional.

A partir deste cenário, definiu-se a seguinte questão de pesquisa: Quais conteúdos contábeis são socializados nos blogs de contabilidade? Teve-se como objetivo identificar os conteúdos contábeis nos blogs de contabilidade. A importância deste estudo se caracteriza

R. Cont. Ufba, Salvador-Ba, v. 9, n. 3, p. 154 - 170, set-dez 2015 
pela dinâmica das formas de socialização e pelo acesso ao conhecimento contábil que são veiculadas nestas mídias. Justifica-se, também, a condição de mídia virtual de rápido e fácil acesso a qual disponibiliza uma variedade de informações e demanda de questionamentos sobre conteúdos contábeis, de forma a requerer uma identificação das diferentes características das linguagens e dos conteúdos compartilhados. Assim, os blogs como forma de manifestação da cultura e como produto de interações sociais, poderão fornecer contribuições ao universo do conhecimento contábil. Diante deste contexto, entende-se o blog como ferramenta das novas tecnologias que favorece a divulgação de materiais, informações, procedimentos, estratégias que se organizam em diferentes abordagens nas áreas do conhecimento, permitindo a troca bem como a acessibilidade de novas experiências para diferentes objetivos e aprendizagens.

\section{REFERENCIAL TEÓRICO}

\subsection{Mídias e interação social}

O desenvolvimento das ciências e das tecnologias torna possível o desdobramento do uso e da funcionalidade das novas descobertas, além do avanço dos meios de comunicação, tendo a internet como centralidade. Também aproxima as redes de comunicação a contextos sociais diversos, bem como possibilita informações que produzam novas formas de pensar e impliquem novos conhecimentos, os quais trarão consequências para a sociedade.

Com isso, um dos pontos favoráveis da formação de redes de comunicação pode ser perceptível pelos dizeres de Levy (1993, p.7), quando expressa que:

\footnotetext{
Novas maneiras de pensar e de conviver estão sendo elaboradas no mundo das telecomunicações e da informática. As relações entre os homens, o trabalho, a própria inteligência dependem, na verdade, da metamorfose incessante de dispositivos informacionais de todos os tipos. Escrita, leitura, visão, audição, criação e aprendizagem são capturadas por uma informática cada vez mais avançada. Não se pode mais conceber a pesquisa científica sem uma aparelhagem complexa que redistribui as antigas divisões entre experiência e teoria.
}

Levy (1993) permite inferir sobre as mudanças que ocorrem no social e que interferem na individualidade dos sujeitos e, sobretudo, na maneira como as pessoas passam a se relacionar com os produtos e as formas de se produzirem os conhecimentos. $\mathrm{Na}$ atualidade, a forma como os sujeitos interagem e aprendem novas formas de se relacionar com o outro e com o conhecimento mantém uma estreita relação com as diferentes mídias advindas do desenvolvimento da internet.

Por outro lado, Castells (2005, p. 26), enfatiza que "nós estamos na sociedade em rede, apesar de nem todos, nem todas as coisas estarem incluídas nas redes.". Essa reflexão é essencialmente necessária quando se busca compreender os processos de grande exclusão das dimensões da vida humana de muitos contextos sociais, sobretudo aqueles que se multiplicam em decorrência das novas estruturas sociais. Para Castells (2005, p.23), também as formas de comunicação podem não representar

[...] o mundo de liberdade entoada pelos profetas da ideologia libertária da Internet. Ela é constituída simultaneamente por um sistema oligopolista de negócios multimédia, que controlam um cada vez mais inclusivo hipertexto, e pela explosão de redes horizontais de comunicação local/global. E,

R. Cont. Ufba, Salvador-Ba, v. 9, n. 3, p. 154 - 170, set-dez 2015 
também, pela interação entre os dois sistemas, num padrão complexo de conexões e desconexões em diferentes contextos.

A reflexão necessária sobre as formas de organização social e política da sociedade requer no tempo presente, proposições e ações que efetivem a democracia como direito inalienável de igualdade para todos. Um direito que se constitui pela pluralidade, inclusive e prioritariamente, pelos modos como a socialização e o acesso aos conhecimentos poderão favorecer uma formação crítica para uma sociedade que se pretende em interação humana.

\subsection{Blogs como Recurso de Interação e Socialização de Conhecimento}

Para Laffin (2013), o blog é um espaço virtual coletivo de comunicação, criado a partir de programas ou ferramentas, geralmente, disponibilizados nas redes sociais virtuais. Esse espaço tem localização por endereço de site na internet e possui titularidade de responsabilidade individual ou coletiva objetivada pela manutenção e pela postagem de informações e conhecimentos. Como espaço virtual coletivo de comunicação, requer critérios para publicar, informar, discutir e analisar os conhecimentos e as informações que propõe socializar.

A identidade do blog, além do endereço na internet, pode ser caracterizada de diferentes formas por meio de metáforas ao tipo de conhecimento/informação que socializa ou de diferentes formas concretas de objetos ou marca patenteada. $\mathrm{O}$ blog como espaço virtual de comunicação prevê mecanismos de facilidade na interação e na produção de comunicação. Tem como característica a diversidade de linguagem e códigos linguísticos, tendo o hipertexto um destaque nas formas dessa comunicação. O blog assume as características de um artefato cultural emergente que decorre da dinâmica das novas tecnologias e tem-se constituído de espaço para o registro do cotidiano (LAFFIN, 2013, p. 1).

O blog, como espaço virtual de comunicação, disponibiliza formas de interação com diferentes públicos que manifestam interesse no diálogo sobre as informações e conhecimentos disponíveis nesta mídia. Com isso, amplia os espaços de reflexão, discussão, aprendizagens e de contra palavra. O resultado dessas diferentes mediações constitui oportunidades de aprendizagem, de forma que a apropriação dos diálogos possíveis nestes espaços de comunicação pode gerar uma reciprocidade e acolhimento para o debate de ideias e proposições.

São inúmeros os temas abordados nesse tipo de mídia. Como mencionado por Rios e Mendes (2014), em pesquisa realizada pelo portal de pesquisa Technorati em 2011 pelo serviço norte-americano especializado no estudo da blogosfera, identificou educação como um dos trinta temas mais comuns de blogs. Atualmente, eles são muito utilizados como recurso pedagógico, Gomes (2005, p.311) relata que:

com o surgimento dos sites de criação, gestão e alojamento de blogs gratuitos e de fácil utilização, a criação de um blog tornou-se uma tarefa acessível a qualquer utilizador da Internet. Em consequência, o conceito de blog tem vindo a evoluir ao ritmo da criatividade e imaginação dos internautas tendo também chamado a atenção de investigadores, professores e outros profissionais com preocupações no domínio da educação.

Quanto à adoção desse tipo de mídia em educação, Gomes (2005, p. 312-313) menciona que o blog pode ser utilizado como "um espaço de acesso à informação especializada ou a um espaço de disponibilização de informação por parte do professor" e como estratégia pode "assumir a forma de portfólio digital, um espaço de intercâmbio e colaboração, um espaço de debate e de integração".

R. Cont. Ufba, Salvador-Ba, v. 9, n. 3, p. 154 - 170, set-dez 2015 
A utilização dos blogs no âmbito educacional, segundo Gutierrez (2005) contribui "para a consolidação de novos papéis para alunos e professores no processo de ensino e aprendizagem, com uma atuação menos diretiva destes e mais participante de todos".

Em complemento, quanto à potencialidade do uso desse tipo de mídia, Araújo (2009, p.14) afirma que:

[...] a utilização de recursos tecnológicos, especificadamente, o blog, com objetivos estritamente educacionais, pode estender o conhecimento para além do espaço físico da sala de aula, criando, assim, um ambiente dialógico e interativo. Dessa forma, o blog estaria dando ênfase à formação do professor/aluno, usando a discussão/interação como um caminho crítico, que conduz os aprendizes do acesso a informação à construção do conhecimento.

Ainda sobre o potencial dos blogs na educação, Rosa (2011) afirma ser uma ótima opção, visto que por serem espaços abertos, além de colaborarem com o espírito crítico e autônomo e se configurarem como uma extensão da sala de aula facilitam a interação, a transmissão de informações e o compartilhamento de ideias.

Diante desse contexto, Bezerra (2011, p. 91) define blogs educativos como "[...] espaços de aprendência com potencial pedagógico para o desenvolvimento cognitivo, fundado na colaboração, na interação, na reflexão, na produção e na socialização do conhecimento pelos (as) aprendentes".

Assim, os blogs educacionais por estarem disponíveis a qualquer pessoa que tenha o respectivo endereço eletrônico, podem revelar contribuições não apenas para professores e alunos, mas também aos diversos usuários interessados nos temas abordados em busca de novas aprendizagens. Deste modo, Leontiev (1978, p.267) aponta que "cada indivíduo aprende a ser um homem. O que a natureza lhe dá quando nasce não basta para viver em sociedade. É lhe preciso adquirir o que foi alcançado no decurso do desenvolvimento histórico da sociedade humana".

Ao estudar os blogs como socialização do conhecimento contábil, referenciou-se à perspectiva histórica cultural que analisa o desenvolvimento do sujeito mediado pelo meio e pelos objetos culturais já apropriados. Desta forma, a socialização de temas e conteúdos contábeis disponíveis em mídias sociais favorece a aprendizagem do sujeito com o meio em que se insere - âmbito social, processos formativos e ambientes profissionais - bem como pelos objetos culturais - conhecimentos contábeis já sistematizados e suas proposições - e resultam de mediações em diferentes formas com o coletivo.

Por conseguinte, os blogs como produto do desenvolvimento, do trabalho e da criatividade humana constituem processos de construção pela apropriação da cultura que é histórica e social. Essa interação social, com os conhecimentos historicamente elaborados, possibilita a construção dos sujeitos e deles as novas atividades. Nessa concepção, o acesso aos temas contábeis proporciona formas de socialização dos sujeitos com a cultura contextual, favorecendo processos de autonomia e de desenvolvimento.

O blog se constitui como novas formas de mobilizar e socializar os sujeitos, ampliando os tempos e os espaços sociais por meio das mídias como lugar de construção. Dessa forma, o blog de Contabilidade, como uma das mídias sociais, integra diferentes sujeitos que objetivam discutir e aprender sobre temáticas em comum, além de favorecer o desenvolvimento e a ampliação de comunidades virtuais.

É necessário refletir, também, a respeito do blog como mídia social que congrega uma comunidade de sujeitos e manifesta concepções sobre o contexto e sobre os conteúdos em evidenciação. É interessante destacar a necessidade de discutir concepções diferentes, sustentadas por argumentos, a respeito de um mesmo objeto sob pena de constituir essa

R. Cont. Ufba, Salvador-Ba, v. 9, n. 3, p. 154 - 170, set-dez 2015 
comunidade em espaços de convergências compactas e absolutas, destituindo a finalidade de socializar e ampliar o acesso aos bens culturais e a funcionalidade nos diferentes contextos sociais. Para Bourdieu (1989, p. 11),

[...] relações de comunicação são sempre relações de poder que dependem na forma e conteúdo do poder material e simbólico acumulado pelos agentes (ou pelas instituições) envolvidos nessas relações e que podem permitir acumular poder simbólico. É enquanto instrumentos estruturados e estruturantes de comunicação e de conhecimento que os "sistemas simbólicos" cumprem a sua função política de instrumentos de imposição ou de legitimação da dominação que contribuem para assegurar a dominação de uma classe sobre outra (violência simbólica) permitem reforço às relações de força que as fundamentam [...] contribuindo para a "domesticação" dos dominados.

Nesse sentido, a socialização por meio dos blogs tem como mediação um conjunto de conteúdos disponíveis e/ou em elaboração, e pode manifestar estruturas de legitimação de crenças, valores e atitudes, que requerem igualmente uma análise para não se converterem em formas sutis de dominação.

Desta forma, o espaço das mídias sociais que não fomentam e propiciam a pluralidade de ideias e a convergência para sistematizar opiniões e conhecimentos sobre o objeto de manifestação, não constitui espaço de socialização, mas sim um produto de consumo acrítico que pode destituir a identidade de sujeito por restringir seu potencial de desenvolvimento.

O blog, como recurso de interação e potencial de aprendizagem, vem-se constituindo em objeto de estudo em diferentes áreas do conhecimento. Destaca-se que muitos dos referenciais teóricos sobre blogs e sua utilização têm sido objeto de estudos em abordagens pedagógicas. Entretanto, neste estudo, não se deseja abordar o uso dos blogs como instrumento pedagógico, mas como forma de socialização do conhecimento e informação contábil.

\section{METODOLOGIA}

Este estudo apresenta natureza exploratória e teve como objetivo identificar os conteúdos contábeis nos blogs de contabilidade. A delimitação do tema vinculado à área contábil, não identificou, por esta pesquisa, estudos anteriores que abordassem o blog de contabilidade como mídia de interação em pesquisas na área contábil.

Com base no objetivo e na questão de pesquisa, delimitaram-se os critérios para a seleção dos blogs a serem pesquisados, tais como a identificação de autoria do blog, número de acessos, data da primeira e última publicação, opção para comentários, possibilidade de discussões e temas relacionados à Contabilidade. A escolha destes critérios foi motivada por constituírem, em sua maioria, os elementos de estrutura e formatação dos blogs seguindo as indicações de Araújo 2009 e Imamura 2011.

A partir desses critérios, realizou-se um levantamento de dados na rede internet a fim de identificar os blogs de Contabilidade com essas características. Durante o mês de abril de 2014, elaborou-se um mapeamento dos blogs de Contabilidade para o qual se utilizou o site de pesquisa Google. O objetivo desse mapeamento consistiu em identificar blogs relacionados à área Contábil e selecioná-los de acordo com os critérios inicialmente definidos. Para delimitar ao critério de seleção dos blogs de Contabilidade, foi predeterminada uma palavrachave com o intuito de selecionar o maior número de resultados eficientes. Eficientes seriam os blogs que estivessem de acordo com os critérios de seleção anteriormente estabelecidos.

R. Cont. Ufba, Salvador-Ba, v. 9, n. 3, p. 154 - 170, set-dez 2015 
Para esta etapa da pesquisa a primeira palavra-chave utilizada foi blog contabilidade, este termo foi escolhido por se constituir objeto de pesquisa. Por meio dela foram encontrados mais de dois milhões de resultados, no entanto, como citado por Imamura (2013) "Além dos resultados relacionados à sua busca, o Google também exibe anúncios relacionados ao que você acabou de pesquisar. Se o anúncio tem muitos cliques ele pode até aparecer acima do primeiro resultado da sua busca. São diversos passos que acontecem para montar o resultado de sua busca e tudo isso acontece em menos de um segundo".

Diante disso, analisando algumas páginas de resultados obtidos, foi possível observar que a maior parte desses resultados não era eficiente. Sendo assim, a cada página contendo dados do Google sobre os blogs, buscou-se selecionar os resultados de acordo com os critérios iniciais. Observou-se que depois da $15^{\mathrm{a}}$ página de resultados não foi possível localizar os blogs que estivessem de acordo com os critérios definidos inicialmente. Nesse contexto, optou-se por analisar apenas as quinze primeiras páginas de resultados, o que resultou em 40 blogs com o perfil estabelecido.

A segunda palavra-chave utilizada foi blog contabilidade fiscal. Ela surgiu por conta dos principais termos encontrados na busca com a primeira palavra-chave. Mediante blog contabilidade fiscal, encontraram-se aproximadamente 800 mil resultados. Para todas as buscas foi utilizado o recurso dos operadores boleanos os quais serviram para combinar e refinar os termos do objeto desta pesquisa. Como ocorreu na primeira busca em que muitos dos resultados que se deparou não estavam de acordo com os critérios definidos. No entanto, pela segunda palavra-chave, descobriu-se uma rede de blogs de Contabilidade intitulada Blogs de Contabilidade ${ }^{1}$ e que, também, já havia sido identificada na primeira busca. Esta rede, como apresentado pela própria rede de blogs, divulga blogs "voltados para reflexão sobre as Ciências Contábeis".

Analisando a rede Blogs de Contabilidade, foi identificado que os conteúdos disponíveis continham informações pautadas em referências acadêmico-científicas. Nela, localizaram-se 60 blogs relacionados à Contabilidade. Todavia, desses 60, apenas 49 estavam de acordo com os critérios de seleção definidos. Ainda assim, percebeu-se que muitos dos blogs encontrados na primeira busca estavam presentes nesta rede. Por esses motivos, optouse em utilizar os resultados obtidos pela rede Blogs de Contabilidade.

Nos 49 blogs, coletaram-se informações a respeito dos autores dos blogs, o ano da primeira e da última publicação e as formas de interação com os seus usuários. Quanto à coleta dos temas relacionados à Contabilidade, optou-se por delimitar a coleta dos temas publicados nos posts do período de janeiro a maio de 2014. Este recorte temporal deu-se em função do índice de atividades das publicações dos posts.

\section{ANÁLISE DOS DADOS: SOCIALIZAÇÃO DE CONTEÚDOS}

\subsection{Períodos inicial e final das publicações nos blogs}

Com o objetivo de se conhecer o período em que os blogs apresentavam suas publicações, como forma de socialização de conteúdos contábeis, identificou-se os períodos de 2006 a 2014 conforme dados do Gráfico 1.

\footnotetext{
${ }^{1}$ Blogs de Contabilidade. Disponível em:<http://blogsdecontabilidade.blogspot.com.br/>. Acesso em: março/ 2014
}

R. Cont. Ufba, Salvador-Ba, v. 9, n. 3, p. 154 - 170, set-dez 2015 


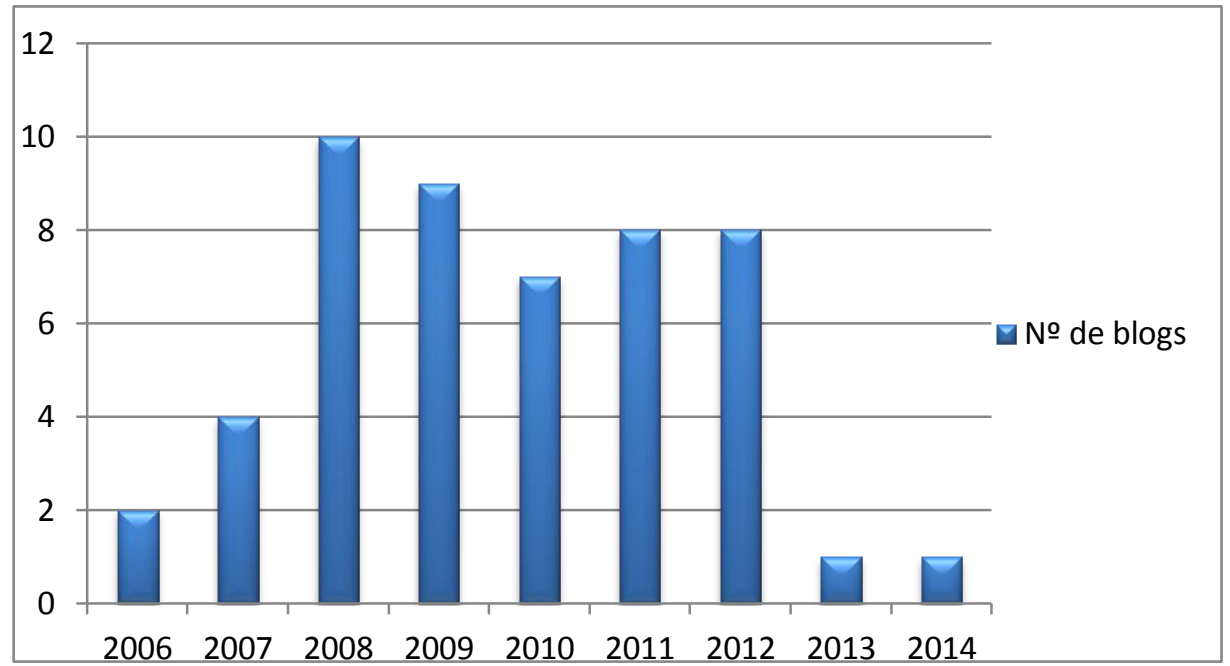

Gráfico 1 - Ano da primeira publicação nos blogs (dados da pesquisa)

Foi possível observar a utilização dessa mídia, inicialmente, no ano de 2006, todavia, o maior número de evidência dos blogs de Contabilidade identificou-se a partir do ano de 2008. Com base nesse dado, questionaram-se quantos desses blogs de Contabilidade continuaram a ser utilizados no ano de 2014. Para responder essa questão, buscou-se pelo ano da última publicação de cada blog, para se conhecer quantos dos 49 blogs pesquisados continuavam a apresentar publicações no ano de 2014.

Através das informações do Gráfico 2, pode-se observar que dos 49 blogs selecionados para análise, $32(65,31 \%)$ apresentavam publicações em 2014 . O que pode ser considerado como um indicador de sucesso quanto ao uso desse tipo de mídia na Contabilidade, considerando os critérios de seleção utilizados para esta pesquisa.

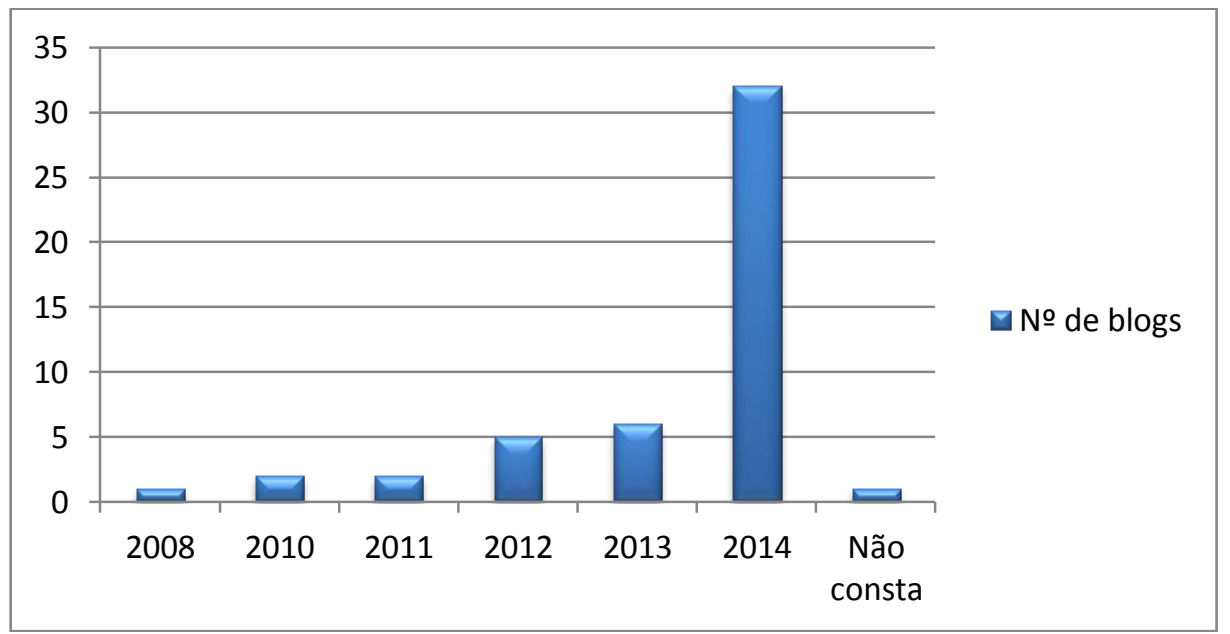

Gráfico 2 - Ano da última publicação nos blogs (dados da pesquisa)

\subsection{Temas abordados nos blogs}

Quanto aos temas identificados na pesquisa e organizados em categorias, como expostos no Gráfico 3, foram categorizados segundo a indicação do próprio blog, não sendo esta classificação objeto de análise neste estudo. Contudo, considerando que a fonte de informação que consta no blog tem a identificação em livros, artigos, leis, decretos, resoluções, entre outros, faz-se uma referência de que adota uma classificação corrente.

R. Cont. Ufba, Salvador-Ba, v. 9, n. 3, p. 154 - 170, set-dez 2015 
A forma como estes temas foram publicados nos blogs são: artigos, notícias, exercícios, resenhas, análises, TCC's, imagens e vídeos. A seguir, o Gráfico 3 mostra os conteúdos contábeis que foram categorizados por pertinência e similaridade e na continuidade são descritas as características de seus conteúdos.

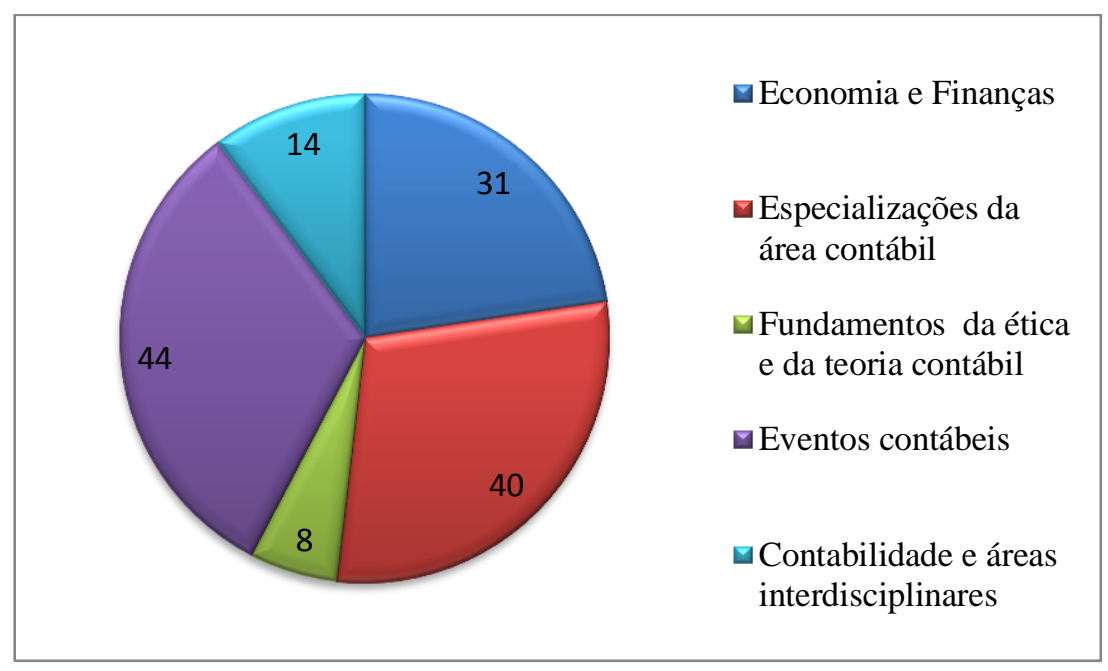

Gráfico 3 - Temas abordados nos blogs (dados da pesquisa)

A categoria "Economia e Finanças" é apresentada nos blogs mediante discussões a respeito de Economia, Finanças e Contabilidade financeira. Os conteúdos dessas três áreas se relacionam em muitas publicações, o que permitiu essa classificação em função de que no post tais conteúdos referem-se a um mesmo objeto de discussão.

Um dos exemplos de conteúdo nas publicações dessa categoria propunha uma discussão referente ao valor de mercado da empresa Yahoo estar abaixo do correto ou superestimado, desafiando os leitores a indagar sobre o correto valor da empresa.

Outro post relacionado a essa categoria alude a empresas familiares. $\mathrm{O}$ autor comentou as características deste tipo de empresa e aponta a disputa pelo poder entre os herdeiros, como problemática de gestão. Além desse post, encontrou-se outro referente ao resultado da empresa Blackberry no ano de 2013. O autor fez uma análise de atuação da empresa nos últimos 10 anos e procurou explicar o motivo do desempenho abaixo do esperado nos últimos anos.

Outra publicação encontrada era referente à liquidez que, segundo o autor, é um dos componentes básicos do valor de um ativo. A questão do impacto da liquidez no valor dos ativos foi ilustrada a partir do caso da família Estevão, que começou a construir sua fortuna baseada em patrimônio imobiliário. Quanto à categoria "Especialização da área contábil", obtiveram-se os seguintes temas: auditoria, tributária, gerencial, pública e ambiental.

Entre as publicações relacionadas à Auditoria estava uma notícia a respeito do licenciamento da auditoria interna. Comenta-se que inúmeros líderes de auditoria interna, em diferentes partes do mundo, promovem a ideia de licenciar os praticantes como uma forma de aumentar a importância e a proficiência da profissão. No entanto, a autora da notícia aborda os benefícios desta mudança, mas faz um alerta aos profissionais sobre os possíveis entraves desta medida.

Outro post da área de Auditoria apresentava um mapa mental para facilitar o estudo a respeito dos tipos de auditoria. No mapa, constam-se Auditoria Contábil, Auditoria de Conformidade, Auditoria Operacional e Auditoria Governamental.

Entre os posts da área Tributária, encontrou-se um conteúdo que apontava índices de $80 \%$ das micro e pequenas empresas do país que serão beneficiadas a partir de 2015 , com a

R. Cont. Ufba, Salvador-Ba, v. 9, n. 3, p. 154 - 170, set-dez 2015 
provável eliminação da substituição tributária ou cobrança antecipada de ICMS. Além desse post, foi encontrado um estudo que menciona o ICMS como sendo a marca do sistema tributário brasileiro, visto que o autor descreve esse imposto como caótico, regressivo e constitucionalmente inadequado. $\mathrm{O}$ autor explica tais afirmações abordando, entre outros, aspectos históricos do ICMS.

$\mathrm{Na}$ área Gerencial, localizou-se um post que apresentava algumas fórmulas de custos, entre elas: custo de transformação, preço de venda, margem de contribuição, custo de produção do período, entre outras. Nesta categoria também foi incluída uma notícia a respeito do pronunciamento da presidente da Petrobrás em 2014, Graça Foster, em que mencionou, entre outros aspectos, não estar preocupada com os custos da companhia. Nessa notícia, há um relato sobre o conteúdo do ponto de equilíbrio, o qual é apresentado como de "US\$ 54 por barril [de petróleo]". Frente às declarações de Foster, o autor do post faz vários questionamentos, entre eles, aborda os possíveis conceitos de pontos de equilíbrio e questiona a que ponto de equilíbrio a presidente da Petrobras se refere.

Relacionada à área de Contabilidade Pública, localizou-se um post que trazia o conceito de Contabilidade Aplicada ao Setor Público (CASP), além de expor a visão do CFC e da Lei $\mathrm{n}^{\circ}$ 4.320/64 a respeito do objeto de estudo da CASP. Outra publicação a cerca da área Pública menciona que às dívidas das 12 capitais sedes da Copa do Mundo no Brasil em dois anos cresceram 51\%, em compensação nas capitais sem a Copa, no mesmo período, a taxa cresceu 20\%. Além dessas dívidas, a notícia aborda outros pontos como a consequência do endividamento dessas capitais sedes.

Quanto à área Ambiental, há um conteúdo referente à Bolsa de valores ambientais - a BVRio. Uma instituição que objetiva criar e operar mercados de ativos ambientais como meio de promover a economia verde no Brasil, tal conteúdo refere-se a um pouco mais a respeito da instituição e sobre as principais atividades que ela exerce. Outro post dessa área alude a custos ambientais com a norma contábil a respeito das provisões (IAS 37), trazendo um exemplo prático sobre o assunto.

A respeito da categoria "Fundamentos da ética e da teoria contábil" foram listados os seguintes tópicos: teoria da Contabilidade e a fraude em Contabilidade e Ética. Entre esses tópicos observou-se uma publicação relacionada à Teoria da Contabilidade que apresenta uma cronologia até os anos 70 da história da Contabilidade no Brasil. Entre os fatos mencionados estava a reforma Administrativa por meio da aprovação da lei 6.430 no ano de 1964. A partir da invasão holandesa, abordou-se a respeito da utilização das partidas dobradas pela primeira vez no Brasil no período de 1624 a 1654.

No que tange ao assunto de fraudes Contábeis, identificou-se um post alertando sobre a manifestação do lembrete dado pelo Conselho Federal de Contabilidade aos contadores e as empresas prestadoras de serviços contábeis, a respeito da necessidade de denunciar operações suspeitas de lavagem de dinheiro, como determina a Resolução 1.445/2013. Outra publicação atinente a fraudes Contábeis refere-se à notícia a respeito da orientação dos contadores às empresas segundo a Lei Anticorrupção 12.846/12. A notícia destaca as possíveis punições das empresas que não respeitarem essa lei e, entre outros pontos citados, orienta os contadores a seguirem a conduta ética e os atos normativos que regem a profissão.

Sobre Ética, encontraram-se alguns posts a respeito da aprovação pelo Plenário do Conselho Federal de Contabilidade de três novas Normas Brasileiras de Contabilidade Profissionais Gerais (NBC PG): NBC PG 100, NBC PG 200 e NBC PG 300. Que estão alinhadas ao Código de Ética da Federação Internacional de Contadores.

Ainda relacionada à Ética, identificou-se outra publicação em que é relatado que mediante a NBC PG 100 o Conselho Federal de Contabilidade aprovou as normas éticas de aplicação geral aos profissionais da Contabilidade. $\mathrm{O}$ autor citou os princípios éticos que devem ser cumpridos pelo profissional da Contabilidade, entre eles estava a integridade, que

R. Cont. Ufba, Salvador-Ba, v. 9, n. 3, p. 154 - 170, set-dez 2015 
consiste em ser franco e honesto em todos os relacionamentos profissionais e comerciais e o sigilo profissional, que consiste em respeitar o sigilo das informações obtidas em decorrência de relacionamentos profissionais e comerciais e, portanto, não divulgar nenhuma dessas informações a terceiros, a menos que haja algum direito ou dever legal ou profissional de divulgação, nem usar as informações para obtenção de vantagem pessoal pelo profissional da contabilidade ou por terceiros.

Em relação à categoria "Eventos Contábeis" foram agrupados os seguintes tópicos: informações a respeito do Curso de Ciências Contábeis, particularidades do profissional contábil, exame de suficiência, concursos públicos e normas internacionais de Contabilidade. A respeito do curso de Ciências Contábeis, encontrou-se uma notícia sobre os conteúdos das disciplinas no curso de Ciências Contábeis, dado que a Contabilidade apresenta mudanças e que os cursos acompanham as alterações. Entre alguns pontos principais da notícia estão as Normas Internacionais de Relatórios Financeiros e o SPED.

Ainda relacionada ao curso de Ciências Contábeis, está uma publicação que procura responder às razões para realizar este curso. O autor apresenta como ponto positivo da profissão a grande empregabilidade, sobretudo em função das mudanças na legislação brasileira e, principalmente, devido às mudanças no mundo causadas pela necessidade de informações rápidas e padronizadas. Dessa forma, o mundo do trabalho aproveita boa parte destes profissionais por conta das novas exigências do fisco e do empresariado.

Sobre as particularidades do profissional contábil, identificou-se uma publicação que trata sobre o futuro do técnico em Contabilidade. O autor menciona que entre os temas abarcados pela Lei 12.249, de 2010, um atingiu diretamente o mundo contábil. Uma das muitas emendas inseridas na medida original determina que, a partir de 2015 , só poderão obter registro profissional em Contabilidade quem possuir o curso superior.

Já em outro post relacionado às particularidades do profissional contábil, aborda que a expansão da economia brasileira e a necessidade de investimentos no país trazem para o Brasil dezenas de empresas de várias partes do mundo. Menciona-se que as empresas de médio porte que aqui chegam enfrentam dois problemas: entender a legislação fiscal e encontrar pessoas capacitadas para atender as normas internacionais. Frente a isso, são citadas algumas das causas para essa falta de profissionais que respondem às demandas do IFRS. Entre estas causas é citado a não adaptação dos currículos das faculdades de Ciências Contábeis às Normas Internacionais.

Em relação ao Exame de Suficiência, encontrou-se um post que informou sobre a publicação do edital da segunda edição de 2014 deste exame. Outra publicação acerca desse assunto discute a nova resolução sobre o Exame de Suficiência do CFC, em que se decidiu que este Exame não será mais exigido dos contadores e dos técnicos em contabilidade que desejam restabelecer o registro profissional. Em que pese a atualidade ou não da publicação, tal conteúdo destaca o movimento discursivo em torno do Exame de Suficiência, o qual tem sido objeto de diferentes questionamentos quanto a forma e legalidade. Além disso, os formandos que concluíram o curso de Bacharelado em Ciências Contábeis ou o de Técnico em Contabilidade até 14 de junho de 2010 não estão mais obrigados a fazer o Exame de Suficiência para obter o registro profissional.

Sobre concursos, detectou-se um post que trazia informações sobre a abertura do edital para concurso público do Tribunal de Contas do Estado do Piauí para diversos cargos, entre eles o de Auditor Fiscal de Controle Externo e contador. Entre outras publicações a respeito deste assunto, estava a notícia da abertura do concurso da Universidade de Brasília para a contratação de três professores efetivos com dedicação exclusiva, podendo se inscrever ao certame, graduados em Contabilidade com mestrado ou doutorado em contabilidade ou áreas afins.

R. Cont. Ufba, Salvador-Ba, v. 9, n. 3, p. 154 - 170, set-dez 2015 
Ainda na categoria "Eventos Contábeis", no que tange o assunto normas internacionais de Contabilidade, encontrou-se uma notícia que comenta a respeito da divulgação da norma sobre reconhecimento de receita de contratos. O autor menciona que o FASB, entidade que regula as normas de Contabilidade dos Estados Unidos e o IASB, que é responsável pelos padrões contábeis de diversos países, inclusive o Brasil, menciona que essa aprovação representará um avanço na convergência contábil entre os principais mercados de capitais do mundo. E provocará uma grande alteração para as empresas de diversos países.

Outro post relacionado às Normas Internacionais encontrou-se a notícia sobre a adequação da Medida Provisória 627 de novembro de 2013, além de explicar acerca dos principais pontos dessa medida.

A categoria "Contabilidade e áreas interdisciplinares" abrange publicações que envolvem Administração e Estatística. Na área de Estatística, achou-se um post a respeito da seguinte questão "Como gostar de métodos quantitativos" O texto traz algumas particularidades do método e, ainda, dá conselhos para resolver o problema daqueles que possuem bloqueio aos métodos quantitativos. Outro post da área de Estatística trouxe quatro guias que compõem a série Making Data Meaningful da United Nations Economic Commission for Europe - UNECE, que segundo o autor do blog, é uma ótima opção para quem precisa elaborar relatórios nos quais sejam apresentados dados, em que geralmente é necessária a elaboração de gráficos e tabelas.

Por fim, a respeito da área de Administração identificou-se uma notícia sobre as medidas, disciplinadas pelo Ministério do Trabalho, a serem adotadas pelas empresas em relação à notificação de doenças e acidentes do trabalho. Além desse, outro post desta área relata a respeito do que ocorre com o empregado de aviso prévio que comete irregularidades.

\subsection{Autoria dos blogs}

Os responsáveis por essas publicações, como evidencia o Quadro 1, foram diversos tipos de indivíduos que possuem interesse nesses tipos de conhecimentos. Todavia, cada um deles apresenta os conteúdos conforme seus objetivos e particularidades.

Entre todos os autores listados, apesar de quatro dos blogs pesquisados não fornecerem informações a respeito destes a grande maioria caracterizaram-se como professores, sendo assim, 17 autores identificaram-se como professores (34,70\%). Posteriormente, os outros dois grupos de usuários mais encontrados na pesquisa foram acadêmicos do curso de Ciências Contábeis $(14,28 \%)$ e contadores $(12,24 \%)$.

O compartilhamento de informações e dos conhecimentos sobre a Contabilidade nos blogs, mediante os diversos autores encontrados, contribui na socialização desse tipo de conhecimento, visto que cada autor possui suas experiências e opiniões a respeito da utilização do conhecimento contábil nos seus respectivos ambientes de aplicação desses saberes, o que possibilita aos usuários dos blogs a apropriação de novos conhecimentos com base nas diferentes perspectivas de cada autor. Além disso, pode contribuir na evolução do conhecimento Contábil, dado que, pelas formas de interação do blog pode ocorrer um estímulo para que os usuários explorem suas ideias a respeito dos diversos temas que abrangem as Ciências Contábeis, contribuindo para que os saberes construídos nessa ciência não sejam vistos como "verdades absolutas", mas como conhecimentos passíveis a reformulações e melhoramento, favorecendo com isso a evolução do Conhecimento Contábil. 


\begin{tabular}{||l|c|}
\hline Autores & Quantidade \\
\hline Acadêmico Curso de Ciências Contábeis & 7 \\
\hline Coordenador do curso de Ciências Contábeis & 2 \\
\hline Contador & 6 \\
\hline Instituição de ensino & 1 \\
\hline Professor & 17 \\
\hline Graduado em Ciências Contábeis & 3 \\
\hline Associação & 1 \\
\hline Mestrando em Ciências Contábeis & 2 \\
\hline Pós-Graduado & 1 \\
\hline Analista Contábil & 1 \\
\hline Advogado & 1 \\
\hline Empresas & 1 \\
\hline Analista Fiscal & 1 \\
\hline Administrador & 1 \\
\hline Auditor & 1 \\
\hline Total & 46 \\
\hline
\end{tabular}

Quadro 1 - Autores dos blogs (dados da pesquisa)

\subsection{Formas de interação do blog}

Diante das formas de interação com os usuários dos blogs, encontraram-se aquelas presentes no Quadro 2. Assim, com relação à referência "opção de comentar", sendo esta uma das características dos blogs, constatou-se, nesta pesquisa, que apesar de existirem frequências de acesso naqueles blogs que registram o número de visitantes, são poucas as manifestações ou comentários sobre os conteúdos ali disponibilizados. As poucas manifestações encontradas dizem respeito a própria informação em postagem, seja em função de alteração de legislação, proposição de questões bem como sugestão de outras publicações do tema em questão. Para fins deste estudo, que teve por objetivo identificar os conteúdos contábeis nos blogs de contabilidade, pode-se inferir que os usuários deste recurso virtual de informação tiveram acesso aos conteúdos da área contábil expostos Gráfico 3, constituindo-se de subsídio para acessar as informações.

Segundo Gomes (2005, p.313), a utilização deste espaço de informação, sobretudo para processos formativos, compõe mais uma alternativa para "possíveis enquadramentos curriculares ou extracurriculares, que apresentem informação cientificamente correta e adequada aos níveis etários com os quais cada professor esteja a trabalhar e que seja da autoria e responsabilidade de pessoas e/ou instituições de mérito e credibilidade".

Os blogs de contabilidade pesquisados possuem a característica de autoria e/ou fonte de identificação e/ou publicação dos textos disponibilizados permite analisar a credibilidade da informação a respeito do tema.

\begin{tabular}{|l||}
\hline 1- Opção de comentar \\
\hline 2- Links de blogs e outros sites relacionados à Contabilidade \\
\hline 3- Enquetes \\
\hline 4-Publicações a respeito das dúvidas dos usuários \\
\hline 5- Postagens e indicações de Vídeos \\
\hline
\end{tabular}

Quadro 2 - Formas de interação com usuários do blog (fonte: dados da pesquisa)

R. Cont. Ufba, Salvador-Ba, v. 9, n. 3, p. 154 - 170, set-dez 2015 
A indicação de "Links de blogs e outros sites relacionados à Contabilidade" inclusos nos blogs pesquisados indicam uma socialização das informações. Essa forma de divulgar fontes de acesso à informação e/ou a conhecimentos permite ao usuário dos blogs constituírem um inventário das publicações temáticas bem como potencializar uma forma de identificação de fontes de pesquisa.

\footnotetext{
Por meio da socialização, as pessoas adquirem conhecimento através do compartilhamento de experiências com outros. A externalização envolve a conversão de conhecimento pessoal (ou tácito) em conhecimento explícito. Através da combinação, o conhecimento explícito é mesclado e articulado com outros conhecimentos registrados. A combinação é, em sua essência, um processo de gestão da informação (BARBOSA, SEPÚLVEDA, COSTA, p.16, 2009).
}

A divulgação de informações e mesmo de fontes de informações possibilita não somente a ampliação e formas de socialização do Conhecimento, mas, sobretudo, coloca a disposição formas de interpretação e/ou questionamentos sobre determinado tema ou conteúdo que está em discussão ou em vias de ser implantado e suas formas de regulação.

Com referência às 'enquetes', como forma de interação nos blogs pesquisados, as proposições encontradas dizem respeito à avaliação do próprio blog, levantamento de temas a serem abordados, a indagações sobre artigos da lei em vigência e, também, a respeito dos procedimentos a adotados em função da convergência às normas internacionais. Essa forma de interação foi identificada, sobretudo, em relação às proposições das normas internacionais. Ressalta-se que a pesquisa não objetivou analisar o conteúdo das enquetes, mas tão somente a enquete como forma de interação nos blogs de contabilidade.

Para tanto, a interação social que se forma pelo acesso e pela socialização de informação e conhecimentos por meio dos blogs tem constituído novas "comunidades digitais" que contribuem para novas aprendizagens sobre objetos temáticos em discussão ou como objeto de estudo. O desenvolvimento das novas tecnologias favorece formas de interação e os blogs de Contabilidade pesquisados indicam a formação de novas comunidades virtuais para discussão de temas contábeis bem como proposição de percursos formativos e intercâmbio de projetos a serem desenvolvidos. A interação resultante das mídias digitais tem reduzido os espaços geográficos, bem como relativizado o tempo e contribuído para os aspectos da formação individual e coletiva.

Outra forma de interação identificada na pesquisa diz respeito às dúvidas postadas pelos usuários dos blogs. Os dados indicam que as dúvidas formuladas, geralmente ao autor do blog, recebem deste uma resposta a qual também é incrementada pela contribuição dos demais usuários do blog. Esse diálogo reflete uma possibilidade não apenas de responder à pergunta formulada, mas também de ampliar a questão e mesmo torná-la objeto de estudo mais específico.

Outra forma de interação identificada na pesquisa diz respeito à socialização de vídeos sobre 'aulas', 'palestras', 'congressos' em que foram discutidos os temas disponibilizados pelo blog. O recurso dos vídeos assume uma importante compreensão do blog como mediação entre diferentes eventos e modalidades em que os temas contábeis são discutidos.

Essa interação entre diferentes pessoas ou grupos aponta o blog como um fértil espaço para socializar ideias e formas de pensar, contribuindo desta forma com o desenvolvimento da área contábil.

\section{CONSIDERAÇÕES FINAIS}

Esta pesquisa buscou identificar os conteúdos contábeis nos blogs de contabilidade cujos resultados permitem concluir que essa mídia evidencia uma socialização de diferentes

R. Cont. Ufba, Salvador-Ba, v. 9, n. 3, p. 154 - 170, set-dez 2015 
conteúdos acerca de conteúdos da área contábil, além de favorecer a constituição de uma comunidade virtual que se relaciona por meio do conhecimento contábil.

Nas formas de interação, mediada pelo conteúdo dos Posts, identificaram-se manifestações colaborativas para o pensamento e prática contábil. Com isso, notou-se que, por meio desse tipo de mídia, surgiram novas formas de socialização entre os sujeitos que objetivam debater e aprender a respeito dos diversos temas relacionados à Contabilidade. Entende-se que essa forma de socialização pode contribuir para o surgimento e ampliação de debates dos conteúdos contábeis, bem como favorece a interação entre comunidades virtuais. Ademais, percebeu-se que a utilização desse tipo de mídia no compartilhamento de diversos conteúdos, indica que o uso dos blogs com conteúdos da área contábil é uma forma de disseminação de conhecimentos, o que pode constituir um aliado às formas já existentes utilizadas com este mesmo objetivo.

Por conseguinte, quanto aos temas abordados observou-se uma pluralidade de conteúdos contábeis, destacando-se os relativos à economia e finanças, especialização e eventos contábeis, que foram apresentados em forma de artigos, notícias, exercícios, resenhas, análises, TCC's, imagens e vídeos.

As contribuições dessa mídia no acesso aos conteúdos de contabilidade estão no compartilhamento de informações e conhecimentos com fonte de identificação e/ou publicação dos textos disponibilizados o que permite analisar a credibilidade e confiabilidade nas informações a respeito dos temas.

Por conseguinte, outra contribuição dos blogs é resultante dos diversos tipos de autores referenciados nos conteúdos, o que possibilita aos usuários o conhecimento quanto à utilização dos diversos saberes relacionado às Ciências Contábeis aplicados nos diversos ambientes relativos aos respectivos usuários.

Constatou-se ainda que a interação social formada por meio dos blogs poderá contribuir na formação individual e coletiva, tendo por referência os diálogos a respeito dos temas compartilhados pelos autores e usuários, o que amplia as questões discutidas a objetos de estudos específicos, além de contribuir na ampliação de discussões da área.

Diante do exposto, é possível propor o desenvolvimento de novos estudos com a utilização de outros tipos de mídias na socialização do conteúdo Contábil, a fim de observar como esses conteúdos constituem uma fonte de pesquisa e discussão do conhecimento Contábil.

\section{REFERÊNCIAS}

AMORIN, L. P. A evolução histórica dos cursos de contabilidade em Santa Catarina. 1. ed. Florianópolis: Conselho Regional de Contabilidade de Santa Catarina, 1999.

ARAÚJO, M. C. M. U. Potencialidades do uso do blog em educação. 2009. 207 p. Dissertação (mestrado em Educação) - Centro de Ciências Sociais Aplicadas, Universidade Federal do Rio Grande do Norte, Natal, 2009.

BARBOSA, R. R.; SEPÚlVEDA, M. I. M.; COSTA, M. U. P. Gestão da informação e do conhecimento na era do compartilhamento e da colaboração. Inf. \& Soc.:Est., João Pessoa, v.19, n.2, p. 13-24, 2009. Disponível em: <http://www.ies.ufpb.br/ojs/index.php/ies/article/viewFile/2378/3034>. Acesso em:out/2014.

BEZERRA, L. T. S. Cultura acadêmica e tecnologias intelectuais digitais: ensinar e aprender com blogs educativos no ensino superior. 2011. 257 p. Tese (doutorado em

R. Cont. Ufba, Salvador-Ba, v. 9, n. 3, p. 154 - 170, set-dez 2015 
Educação) - Programa de Pós-Graduação em Educação, Universidade Federal da Paraíba, João Pessoa, 2011.Disponível em: $<$ http://bdtd.biblioteca.ufpb.br/tde_busca/arquivo.php?codArquivo=2225>. Acesso em: setembro/2014.

BOURDIEU, P. O poder simbólico. Lisboa: Difel, 1989.

BUENO, F.S. Grande dicionário etimológico-prosódico da língua portuguesa. Vocábulos, expressões da Língua Geral e Científica-sinônimos, contribuições do Tupi-Guarani.v.3, São Paulo: Saraiva, 1965

CASTELLS, M. A sociedade em rede. São Paulo: Paz e Terra, 1999.

A sociedade em rede: do conhecimento à política. CASTELLS, Manuel; CARDOSO, Gustavo (Orgs.). A sociedade em rede: do conhecimento à ação política. Conferência promovida pelo Presidente da República, 4 e 5 de março de 2005. Imprensa Nacional - Casa da Moeda, $2005 . \quad$ Disponível em: <http://www.egov.ufsc.br/portal/sites/default/files/anexos/a_sociedade_em_rede__do_conhecimento_a_acao_politica.pdf>.Acesso em: 10 mar. 2013.

CIRIBELI, J. P.; PAIVA, V. H. P. Redes e mídias sociais na internet: realidades e perspectivas de um mundo conectado. Mediação, v.13, n.12, p. 58-74, 2011.Disponível em: $<$ http://www.fumec.br/revistas/index.php/mediacao/article/view/509/504>. Acesso em: setembro/2013.

GOMES, M. J. Blogs: um recurso e uma estratégia pedagógica In: MENDES, A.; PEREIRA, I.; COSTA, R. (editores). Actas do VII Simpósio Internacional de Informática educativa, Leiria: Escola Superior de Educação de Leiria, 2005, pp.311- 315.. Disponível em: < https://repositorium.sdum.uminho.pt/bitstream/1822/4499/1/Blogs-final.pdf >.Acesso em: setembro/2014.

IMAMURA, D. Como funciona a busca do Google? Portal Oficina da Net Publicado em 07 de junho de 2011. Com atualização em 27 de abril de 2013. Disponível em: Acesso em: novembro/2013.

LAFFIN, M. Mídia eletrônica e contabilidade. Projeto de Pesquisa - NETEC - Núcleo de Estudos Sobre Trabalho e Ensino em Contabilidade - Departamento de Ciências Contábeis UFSC, 2013.

LEONTIEV, A. O desenvolvimento do psiquismo. Trad. Manuel D. Duarte. Lisboa: Horizonte Universitário, 1978.

LÉVY, P. As tecnologias da inteligência. O futuro do pensamento na era da informática. Rio de Janeiro: Editora 34, 1993.

Cibercultura.São Paulo: 34, 1999.

MARTINS, M. F. O. Um passeio na Contabilidade, da Pré- historia ao novo milênio. Adcontar, Belem, v. 2, n 1, p. 7 -10, maio 2001. Disponível em: < http://www.nead.unama.br/site/bibdigital/pdf/artigos_revistas/248.pdf > .

Acesso: setembro/2013.

R. Cont. Ufba, Salvador-Ba, v. 9, n. 3, p. 154 - 170, set-dez 2015 
RIOS, G. A.; MENDES, E. G. Uso de blogs na educação: Breve panorama da produção científica brasileira na última década. Revista Eletrônica de Educação, São Carlos, v. 8, n. 2, p. 160-174, 2014. Disponível <http://www.reveduc.ufscar.br/index.php/reveduc/article/viewFile/746/331>. Acesso em: setembro/2014.

ROSA, L. S. Um Estudo sobre o Edublog e o ensino de língua estrangeira espanhol. 2011. 142 p. Dissertação (pós-graduação em Educação) - Universidade Federal de Santa Catarina, Florianópolis. 2011.

SCHAFF, A. A sociedade informática: as consequências sociais da segunda revolução industrial. São Paulo: UNESP, 1993.

VILALBA, R. Teoria da Comunicação. São Paulo: Ática, 2006.

VIGOTSKI, L. S. A formação social da mente: o desenvolvimento dos processos psicológicos superiores. São Paulo: Martins Fontes, 1998.

WERNECK, V. R. Cultura e valor. Rio de Janeiro: Forense Universitária, 2003. 